\title{
Preliminary assessment of a microgrid integrated with a biomass gasification CHP system for a production facility in Central Italy
}

\author{
Ettore Stamponi ${ }^{1}$, Francesco Giorgini ${ }^{2}$, Franco Cotana $^{3}$, and Elisa Moretti ${ }^{3 *}$ \\ ${ }^{1}$ CIRIAF - Interuniversity Research Centre, University of Perugia, Via G. Duranti 63 (Perugia, Italia) \\ ${ }^{2}$ Loccioni, Via Fiume 16, Angeli di Rosora (Ancona, Italia) \\ ${ }^{3}$ Department of Engineering - University of Perugia, Via G. Duranti 93 (Perugia, Italia)
}

\begin{abstract}
The aim to reduce carbon dioxide emissions and to improve buildings energy efficiency has led to develop smart grids to manage electricity and heat. The work deals with the thermal and electric microgrid analysis of the Loccioni Company: the production facility consists of high-energy performance industrial and office buildings, partially powered by produced on-site renewable energy (solar PV, hydropower plants, water ground heat pumps). The challenge of continuous improvement in the use of energy led the company to develop a thermal microgrid for optimal management of the heat produced by a small-scale CHP system (50 kWel/110 kWth). The cogeneration system is based on biomass (pellet) chemical degradation process of gasification. The work discusses preliminary results relating to the first months of the system operation, to highlight the energy benefits and the critical issues. Data are collected by the Company monitoring system and a laboratory feedstock physico-chemical characterization is carried out. The main goal of this paper is to lay the foundations for the development of an energy management system that regulates energy flows between buildings. The development of the thermal microgrid will guarantee not only tangible benefits in terms of energy savings but also an increase in the resilience of the entire building/plant system.
\end{abstract}

\section{Introduction}

To stop climate change, the European Union (EU) is committed to cut greenhouse gas emissions significantly. The built environment accounts for approximately $40 \%$ of energy consumption and $36 \%$ of $\mathrm{CO}_{2}$ emissions in the EU [1]. That is why sustainable, climate-proofed buildings are needed - on a massive scale - to meet the targets set out for 2020, 2030, and achieve a climate-neutral Europe by 2050. To reach this ambitious objective, a shift in energy consumption towards low carbon, locally produced energy and Renewable Energy Sources (RES) is needed [2]. Such target could be achieved using smart grids. A smart grid is a semi-autonomous system of distributed generators and dispatchable loads, acting together to bring reliable and secure power supply and heating to a local community. Besides, a smart grid can also have an energy storage device and it can work grid-connected or island mode [3]. System generators are usually composed of Renewable power plants monitored and controlled in real-time. In the energy management procedures field, the optimal scheduling of smart grid operation is an attractive issue [4].

Combined Heat and Power generation system (CHP), supplied by biomass, is one of the tools to reach the European targets and reduce $\mathrm{CO}_{2}$ emissions. Biomass gasification for power generation is considered as one of the cheapest and green alternatives to fossil fuels. In the last few years biomass gasification technology has developed rapidly and nowadays it represents an energy source, which can be well converted to electricity. Biomass energy is actually very suitable for distributed and localized utilization, and small-scale biomass gasification generation is a possible technology for the local electricity and thermal supply $[5,6]$.

This paper sums up the monitoring campaign of a small-scale gasification plant, producing up to $50 \mathrm{~kW}_{\mathrm{e}}$ of electric power and $110 \mathrm{~kW}_{\mathrm{t}}$ of thermal energy. The whole process was analysed through the laboratory characterization of biomass input, through the real-time syngas monitoring, electrical efficiency estimation and analysis of the thermal microgrid energy flows between buildings. The main goal of this paper is to lay the

\footnotetext{
*Corresponding author: elisa.moretti@unipg.it
} 
foundations for the development of an energy management system that regulates energy flows between buildings, based on demand-side management strategies.

\section{Case Study}

The Loccioni Campus (Figure 1) is located in Angeli di Rosora (AN), a small town in Italy near by the company headquarters. The campus consists of six buildings, connected by an electric smart grid that allows to better manage the consumption and the production from the renewable energy plants [7]. The Campus is designed to be powered only by electricity, indeed, since 2019, consumption of natural gas has been reduced to zero and all utilities, including HVAC systems, are powered by electricity. Furthermore, a thermal smart grid that delivers the heat produced by the recently installed CHP system connects the buildings.

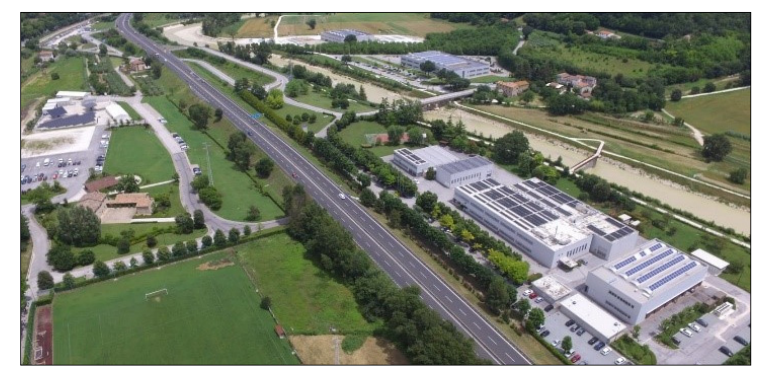

Fig. 1. Loccioni Campus.

\subsection{Buildings and facilities}

L2 is the first building built in 1984. It has an area of $1520 \mathrm{~m}^{2}$ and hosts the company's development teams: governance, communication, management and training of people and networks. Since 2005 it has undergone upgrading like the natural gas boiler replacement by water-water heat pumps (HP) (powered by ground water), the old windows have been replaced by energyefficient windows and solar shades managed by the new building automation system. On the rooftop there is a $36,3 \mathrm{kWp}$ photovoltaic system.

L3 was built between 1989 and 1994, it consists of three structures with a total surface of $4120 \mathrm{~m}^{2}$. It hosts offices and production departments. It is the same L2 construction type and has undergone similar renovation works. On the rooftop there is a $112,1 \mathrm{kWp}$ photovoltaic plant. The lighting is guaranteed by LED lamps and by large windows and solar tubes installed on the roofs, as in L2.

L5 was born in 2015 as an extension of the adjacent L3 laboratory and built-in compliance with the existing one. The new laboratory, measuring 45,70 x 23,10 m, contains a production space and a part intended for offices and services. The production area houses six test rooms and two laboratories made by operating in a controlled atmosphere. On the rooftop and in the southeast facade two sections of a PV system are installed.

Leaf Farm was born in 2010, from the renovation of an existing rural complex. The building (total area 150 $\mathrm{m}^{2}$ ) houses meeting rooms and open space offices. Some intervention features are ventilation systems with heat recovery installation, air conditioning through an aircooled heat pump and dimmerable lighting.

L4 was built in 2013 on the opposite bank of the Esino river. The building has an area of $6000 \mathrm{~m}^{2}$ and is certified in class $\mathrm{A}+$, thanks to the most modern technologies, which reduce energy consumption for air conditioning, ventilation and lighting. Three reversible water-water heat pumps, powered by ground water, powered the HVAC system and, on the rooftop, there is a $235,5 \mathrm{kWp}$ photovoltaic system. The advanced monitoring and control systems of internal parameters (temperature and lighting) make L4 a Nearly-Zero Energy Building (nZEB) (Figure 2). Furthermore, under the car parking beside L4, there is a $450 \mathrm{~m}^{3}$ thermal storage, in an insulated tank made by reinforced concrete.

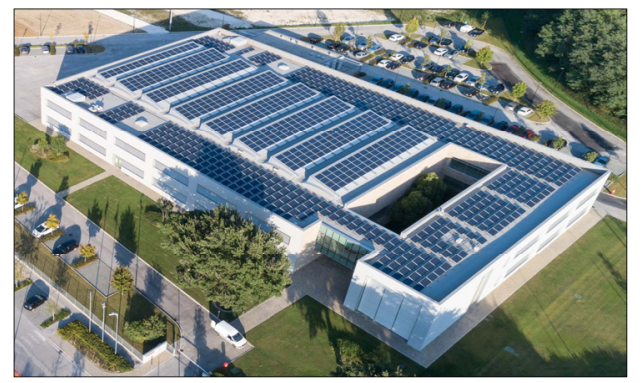

Fig. 2. L4.

L6 is the last built, in 2018. It has the same construction features and designated use of L4 but is even more efficient. In this building there is no thermal storage but a $500 \mathrm{kWh}$ battery energy system (BES).

All the Loccioni Campus buildings and the power plants (Table 1) are connected to the only point of delivery (POD) with the national power grid.

Table 1. Plants and storage (electric smart grid).

\begin{tabular}{lll}
\hline Plants & Type & Size \\
\hline L4 roof & Photovoltaic & $235,5 \mathrm{kWp}$ \\
Roof 16 & Photovoltaic & $207,9 \mathrm{kWp}$ \\
L2 L3 roof & Photovoltaic & $148,3 \mathrm{kWp}$ \\
Farm on land & Photovoltaic & $80,5 \mathrm{kWp}$ \\
Wood gasifier & CHP & $50,0 \mathrm{kWp}$ \\
Leaf water 4 & Hydroelectric & $45,0 \mathrm{kWp}$ \\
L5 roof & Photovoltaic & $37,5 \mathrm{kWp}$ \\
Solar mover 2 & Photovoltaic & $18,2 \mathrm{kWp}$ \\
Solar mover 1 & Photovoltaic & $18,0 \mathrm{kWp}$ \\
L5 vert. & Photovoltaic & $10,7 \mathrm{kWp}$ \\
Farm storage & BES & $224,0 \mathrm{kWh}$ \\
L6 storage & BES & $500,0 \mathrm{kWh}$ \\
\hline
\end{tabular}

In this way, the energy, produced by the plants, enters the national network only if there are no users able to use it and BES are fully charged. Similarly, during hours of insufficient production, energy stored in the BES is used before buying it. The Campus annual energy consumption is $2518 \mathrm{MWh}_{\mathrm{e}}$. The $38,5 \%$ is for the HVAC systems, $11,6 \%$ for lighting and 49,9 is for 
offices and laboratories. Thanks to that, the selfconsumption of renewable energy produced was $87 \%$ in 2019, and self-sufficiency was 35\% (2019). The smart grid is also used to power the charging stations of electric cars that are part of the company car fleet.

\subsection{Thermal microgrid}

The thermal microgrid connects the cogeneration plant with the thermal power plants of the buildings, thus managing to distribute the thermal energy produced by the plant to the buildings. Besides, the thermal storage tank in L4 allows storing the energy produced during the night (Table 2), on holidays and when production exceeding the demand. Thermal storage, powered by groundwater, has dimensions 12,3 x 11,0 x 3,4 m for a volume of $460 \mathrm{~m}^{3}$, it is insulated with a $16 \mathrm{~cm}$ layer of XPS c350 ( $\mathrm{U}=0,032 \mathrm{~W} / \mathrm{mK})$ and is positioned below ground level to minimize heat losses.

The grid pipes (Figure 3) extend for over $2 \mathrm{~km}$; have an internal diameter of $2^{\prime \prime}$ and insulation made of extruded elastomeric material with a thickness of $6 "$ with a conductivity lower than $0,040 \mathrm{~W} / \mathrm{m}^{\circ} \mathrm{C}$.

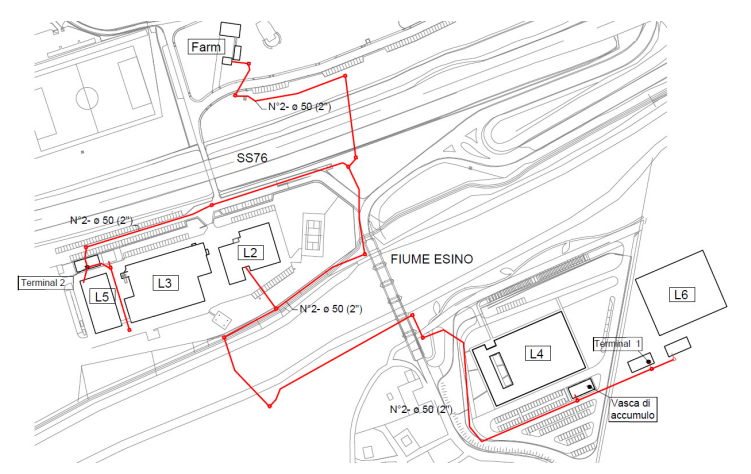

Fig. 3. Thermal microgrid.

The heart of the thermal grid is "terminal 1" which is located between buildings L4 and L6. In terminal 1 a container houses the cogeneration plant and in the basement compartment below it, there is the technical room of the thermal grid (Figure 4$)$. The water $\left(85^{\circ} \mathrm{C}\right)$ in output from the CHP, passes through the "SC1" heat exchanger and transfers its thermal energy to the grid. $\mathrm{SC} 1$ has a power of $110 \mathrm{~kW}$ as well as the two dry coolers that start operating when the grid is not active and it is necessary to dissipate heat produced by the cogeneration unit. The main twin pump of the grid (P1A and $\mathrm{P} 1 \mathrm{~B}$ ) has a flow rate of $9,5 \mathrm{~m}^{3} / \mathrm{h}$ and an head of 600 $\mathrm{kPa}$. The pump is equipped with an inverter that regulates the absorbed power based on the flow necessary for the grid, which varies according to the distance of the building to be powered. Pump consumption is approximately $0,8 \mathrm{~kW}$ to feed the nearest building, $7,0 \mathrm{~kW}$ for the farthest.

In the grid, energy is distributed according to a hierarchical logic. Firstly, L6 and L4 thermal demand are satisfied. These are the two buildings closest to the cogenerator, where thermal energy can be supplied with maximum efficiency while minimizing leakage. When the demand for these two buildings is zero, the grid starts feeding buildings beyond the river (in this order L3, L5, Farm), always according to the logic of the closest proximity. When demand for all buildings is zero, the energy produced by the CHP system, feed the thermal storage. The buildings heat exchangers have been sized according to the thermal loads required by the latter; those of L6, L4 and L3 have a power of $110 \mathrm{~kW}$ while those of the farm and L5 are $50 \mathrm{~kW}$. The grid was also designed to increase the resilience of the entire system, indeed, if a building's air conditioning system has some issues, L6, L4 and L3 could go to its aid by giving heat to the grid [8].

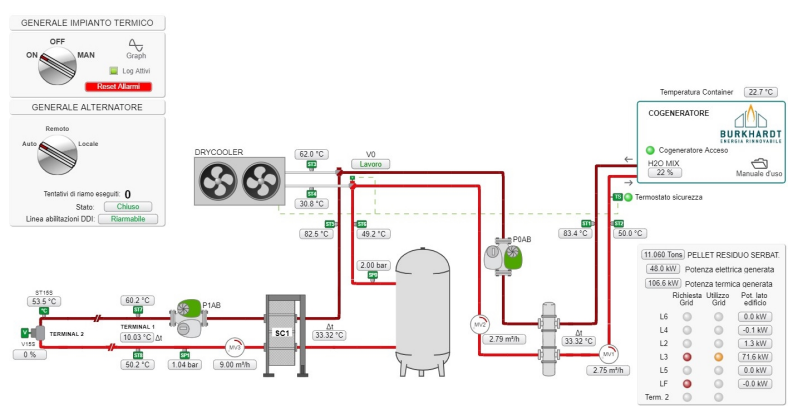

Fig. 4. Thermal microgrid, technical room (screen from Loccioni BMS system).

Table 2. Plants and storage (thermal microgrid).

\begin{tabular}{lll}
\hline Plants & Type & Size \\
\hline Wood gasifier & CHP & $110,0 \mathrm{kWt}$ \\
L4 storage & Thermal storage & $450 \mathrm{~m}^{3}$ \\
\hline
\end{tabular}

\subsection{CHP plant}

The cogeneration is carried out through a system composed of a pyrogasifier Burkhardt V4.50 (Figure 5) [9], whose thermal power is $25 \mathrm{~kW}$, pellet-fed, and by a Smartblock 50T cogeneration unit with a thermal and electrical power equal to $85 \mathrm{~kW}_{\mathrm{t}}$ and $50 \mathrm{~kW}_{\mathrm{e}}$.

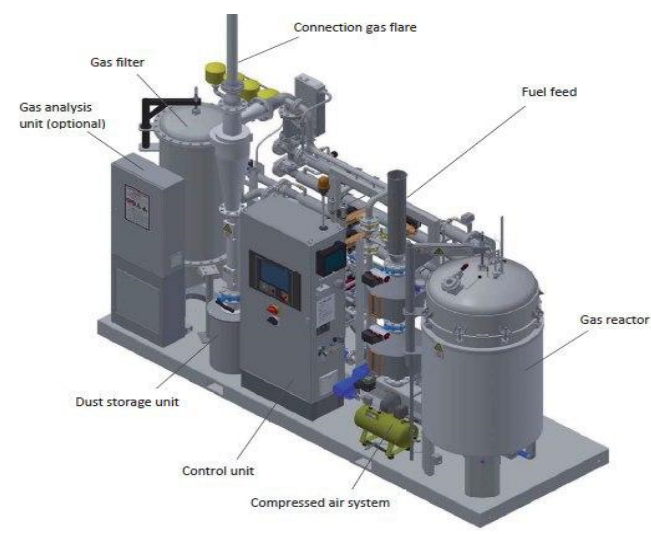

Fig. 5. Pyrogasifier burkhardt V4.50.

At nominal operation, the consumption of pellets is $0,8 \mathrm{~kg} / \mathrm{kW}_{\mathrm{e}}$ [10]. The plant, in operation since 31 October 2019, was placed between the buildings L4 and L6 in a steel container of $8,50 \times 3,00 \times 3,4 \mathrm{~m}$ in size, completely soundproofed and thermally insulated. The device is connected to both the electric and thermal grid.

The pellet used to power the system is made of fir and is EN Plus A1 certified. The EN Plus certification defines three different quality classes of the pellet and is 
based on the European technical standard EN 14961. This ensures that the entire production chain of the pellets is controlled and that the product meets certain parameters.

The biomass is stored inside a container, close to the cogenerator module, with dimensions of $2.8 \times 3.5 \times 10$ $\mathrm{m}$. The maximum storage capacity is 40 tons. The deposit is also housed on 8 different load cells that monitor its weight and therefore the biomass stored inside. On the upper portion, two openings allow, through a pumping system, to load the pellet through two pipes that unload the biomass at the beginning and in the middle of the container, to obtain the most homogeneous distribution possible. The pumping takes place at a minimum pressure of 0,4 bar to minimize tensions and impacts, that would otherwise cause a strong deterioration of the mechanical parameters of the biomass. Two augers run longitudinally at the base of the container and, merging into a single pipe, transport the biomass to the reactor. In the middle of the transport pipe, there is a screening system, necessary to remove dust produced during the transport and loading.

The reactor is made of steel, shielded internally with refractory ceramic material and insulated with a coat. Inside, the gasification takes place in ascending direct current: the fuel and the combustion air, both entering from the bottom, dosed in such a way that the pellet itself fluidizes in some areas so as not to be dragged away.

There are 10 sensors inside the reactor, positioned at different heights, which constantly monitor the temperatures of the various process stages. The produced syngas by the gasification process, having a temperature of about $800{ }^{\circ} \mathrm{C}$, is extracted from above and passed through a series of heat exchangers, allowing to recover $25 \mathrm{~kW}$ of thermal power, and thus reducing it the temperature up to $125^{\circ} \mathrm{C}$. Subsequently, before entering the engine, the gas is cleaned by a bag filter. A mechanical system cleans the bag in turn, coming into operation whenever the difference of pressure between incoming and outgoing syngas reaches the breakpoint value. Once purified, the biogas enters the Smartblock 50T cogeneration unit.

The main components (engine, generator, air supply unit and heat exchangers for the exhaust gases) are completely integrated into the module. A specially developed sound-absorbing cover reduces noise emissions from CHP.

\section{Materials and methods}

Given the great attention that the company pays to energy management, there are several measuring sensors in the Loccioni Campus. The widespread collection of data is essential for the activities analysis in order to control environmental and production parameters, making it possible to automate many processes. The stored data are managed within a company database called "myLeaf"[11].

\subsection{Monitoring campaigns}

The monitoring campaign began on 2019, November $20^{\text {th }}$ to 2020 , April $15^{\text {th }}$, when the plant was shut down for the end of the heating season. During this period, the consumption of pellets from the gasifier, the syngas produced, and the production of thermal and electrical energy from the CHP were examined. In this way, the plant performance indices, i.e. $\mathrm{kg}$ pellet $/ \mathrm{kWh}$, were calculated. The functioning of the thermal grid was also monitored, especially the dispersions and energy flows exchanged between the grid and buildings.

Finally, the thermal and electrical demand of the buildings were monitored and then compared with the same period of 2019 (when the grid was not working) in order to estimate the impact of the grid on energy consumption.

\subsection{Biomass characterization}

The pellet used to feed the Burkhardt V4.50 gasifier was subjected to analyses aimed at studying its physicalchemical and energy properties at the Centro Ricerca Biomasse (CRB) of the University of Perugia. During the tests, the following characteristics were evaluated: - mechanical durability;

- gross calorific value.

The mechanical durability was measured for different samples in compliance with EN 15210 by using the New Holmen Tester Tekpro lignotester

The gross calorific value was measured following EN 18125. The test was carried out using the LECO AC350 calorimeter, by measuring the heat generated by the combustion of the sample, which took place in a controlled environment, Mahler's Bomb, and transmitted to the water of the calorimetric box where the bomb is immersed.

\section{Results and discussion}

In the first two months of operation (November and December), it was necessary to calibrate all the parameters of the system and the thermal microgrid. These operations were essential to understanding all the peculiarities that a plant of this small size has. Before the Christmas holiday, the whole system was turned off, due to the lower energy demand of the company; and it was restarted on January $14^{\text {th }}$.

On February $17^{\text {th }}$, the system was reset and maintenance of the $1000 \mathrm{~h}$ of the engine was carried out. In those days the reactor, the pellet storage, the bag filters and gasifier were cleaned.

\subsection{Monitoring results}

Through the monitoring campaign, the CHP system produces about $120 \mathrm{MWh}_{\mathrm{e}}$, consuming about 85 tons of pellets. Figure 6 shows the main daily electric production during the monitored period. As shown, only for a few days or a few hours per day CHP system works at nominal power. The average daily electrical power, supplied by the cogeneration unit in the first three 
months, does not exceed $90 \%$ of the nominal one. This is because during the first phase CHP works following the nominal power of $50 \mathrm{~kW}$. The result of this setup was an irregular operation, with automatic shutdowns caused by the latter's inability to lower the pressure difference between the incoming syngas and the outgoing syngas from the bag filter. This was due to the excessive presence of dust output from the gasification process and to the TARs that fouling the bag filter located between the gasifier and CHP unit.

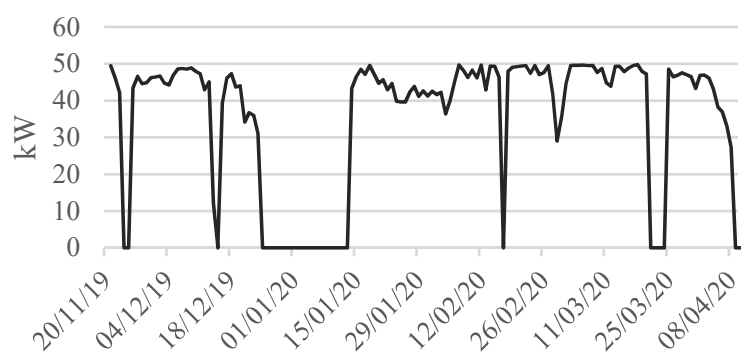

Fig. 6. Daily main electric production.

The chemical composition of the syngas is monitored through the analyser integrated into the gasifier. The results (Figure 7) are in agreement with the literature data [12].

With regards to thermal energy, the microgrid made it possible to use about $64 \%$ of the heat produced ( 258 $\mathrm{MWh}_{\mathrm{t}}$ ) (Figure 8).

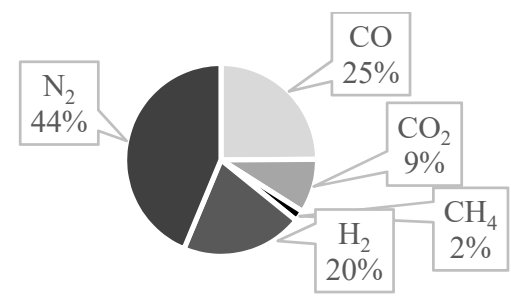

Fig. 7.Syngas composition.

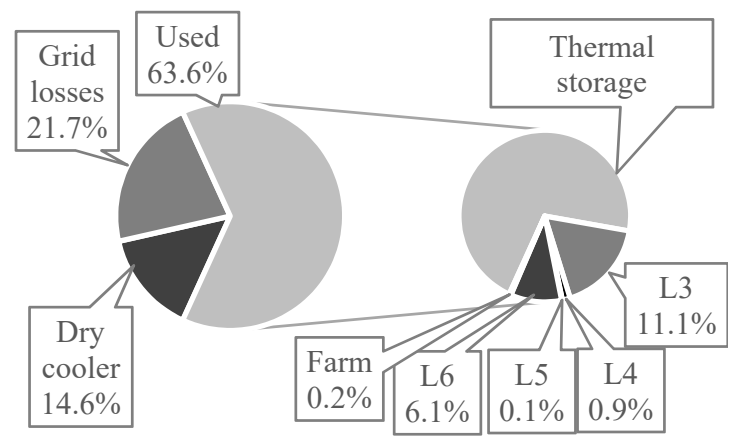

Fig. 8. Thermal energy usage.

Whenever the engine stops for any reason and the gasifier continues to produce energy, the air-cooling system dissipated the energy produced. The energy losses are physiological of the grid and the use of energy by L3 cause most of it. Indeed, due to the losses in the heat exchangers, in the pumps and along the grid, only $70 \mathrm{~kW}$ of $110 \mathrm{~kW}$ get to the building, with a loss of around $40 \%$. Instead, when the grid powered the storage, located below L4, the losses are of the order of $5 \%$.

\subsection{Analysis of benefit and critical issues}

The use of CHP system, the thermal microgrid and thermal storage reduced the load peaks. The limited size of the plant and the possibility of storage any share of overproduction (in the L6 BES), caused an increase in self-sufficiency and self-consumption of the smart grid.

The increase of self-consumption and energy selfsufficiency is also due to the use of recovered thermal energy produced by the CHP. Indeed, in February, the thermal energy supplied to L4 by thermal storage covered $91 \%$ of the building's thermal load, almost totally reducing the electrical demand of the heat pumps.

In order to estimate the impact of the proposed systems, two days of 2020 in which the thermal storage powered L4 HVAC systems were compared to two days of 2019 (without microgrid and CHP); the chosen periods have similar outdoor temperature trends and thermal loads (increase of $15 \%$ ), whereas the electrical savings amounted to about $80 \%$ (Table 3 ).

Table 3. L4 thermal load and heat pump consumption.

\begin{tabular}{ccccc}
\hline \multirow{2}{*}{ Days } & \multicolumn{3}{c}{ L4 demand $[\mathrm{kWh}$ t } & \multirow{2}{*}{ L4 HP demand } \\
\cline { 2 - 4 } & HP & Storage & Total & {$[\mathrm{kWh}]$} \\
\hline 14/15 Jan 19 & 5016 & $/$ & 5016 & 957 \\
20/21 Jan 20 & 719 & 5111 & 5830 & 180 \\
\hline
\end{tabular}

The monthly consumption of pellet used to produce $1 \mathrm{kWh}$ of electrical energy is in agreement with the theoretical value $(0,8 \mathrm{~kW} / \mathrm{kg}$ pellet $)$ only in March. While it is more than 0,89 in the other months (Figure 9).

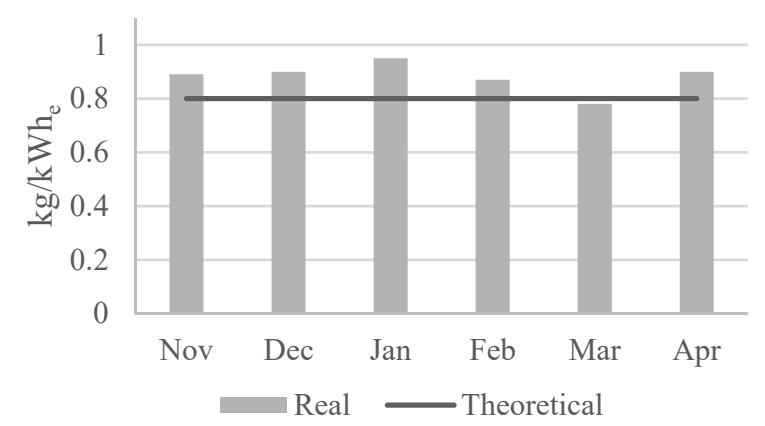

Fig. 9. Unitary monthly pellet consumption.

The months with higher values are those with higher numbers of system shutdowns. In most cases, shutdowns are due to the system's inability to lower the pressure difference between the incoming and outgoing syngas from the bag filter placed before the engine.

Indeed, the investigated system requires biomass that has particularly high physical and energy parameters, unlike, for example, other wood powered systems. Therefore, it cannot be purchase by local producers, limiting economic and environmental sustainability. The analyses carried out to characterize pellets have shown performance values by those required: the mechanical durability was greater than $99 \%$, while the gross calorific value is $5,2 \mathrm{kWh} / \mathrm{kg}$ (the laboratory analyses were carried out according to section 3.2). However, the actual operating conditions are different from the conditions reproduced during laboratory tests. Following the direct observation of the 
loading activity of the container used for storage, it is reasonable to assume that this is the cause of excessive production of dust and a worsening of the mechanical parameters of the biomass, causing an excessively dirty syngas.

\section{Conclusion and future development}

The use of biomass, as a renewable source, allows obtaining a constant electrical production, regardless of wheatear conditions, thus making up for any temporary and production lacks by the photovoltaic and hydroelectric plants.

The paper shows the results of the first period of operations of a small-scale biomass gasification system for power generation in a thermal and electric grid. The preliminary results have shown that after the deep maintenance and cleaning, which was carried out at the end of February, the system has improved the quality and quantity of its production. Therefore, a higher frequency of maintenance operations, then the frequency indicated by the manufacturer, would guarantee an increase in productivity.

The dust generated during the loading of the pellets into the container and the transport in the reactor are responsible for the fouling of the system, which requires maintenance more frequent. The fouling of the bag filter may also be caused by TARs produced during the gasification process. Therefore, since it is impossible to replace or modify the current loading system, it should be appropriate to add an additional screening system immediately before the entry of the biomass into the reactor.

For better use of the system, it would be interesting to evaluate the upgrade to a trigeneration system. The grid could distribute chilled water to the buildings closest to the CCHP system (Combined cooling, heat and power system). Intervention, however, should be carefully evaluated and analysed. A CCHP system, indeed, has a lower generation efficiency than a CHP system. Finally, the environmental impact of the refrigeration system should be considered, especially the use of the evaporative tower, which requires not negligible quantity of water.

The authors wish to thank Nicola Lattanzi and Nicola Di Lisa for their precious contribution during the experimental campaigns. Moreover, thanks to Loccioni group (https://www.loccioni.com) for the willingness to provide the necessary information to the success of the work and for the hospitality received during the inspections at Angeli di Rosora. Special thanks to Team Facility for the valuable support provided during the monitoring campaign.

\section{References}

1. [https://ec.europa.eu/easme/en/news/sustainablebuildings-europe-s-climate-neutral-future]

2. R. Segurado, S. Pereira, D. Correia, M. Costa, Techno-economic analysis of a trigeneration system based on biomass gasification. Renewable and Sustainable Energy Reviews (2019). doi:10.1016/j.rser.2019.01.008
3. A. Ahmad Khan, et al. A compendium of optimization objectives, constraints, tools and algorithms for energy management in microgrids. Renewable and Sustainable Energy Reviews (2015). doi:10.1016/j.rser.2015.12.259L

4. B. Aluisio, M. Dicorato, G. Forte, M. Trovato, An optimization procedure for Microgrid day-ahead operation in the presence of CHP facilities. Sustainable Energy, Grids and Networks (2017). doi:10.1016/j.segan.2017.07.003

5. A. Yohanes, Z. Zhongkai, et al., Small-scale biomass gasification systems for power generation $(<200 \mathrm{~kW}$ class $):$ A review, Renewable and Sustainable Energy Reviews, n. 117, (2020), doi.org/10.1016/j.rser.2019.109486

6. G. Marseglia, C.M. Medaglia, A. Petrozzi, A. Nicolini, F. Cotana, F. Sormani, Experimental Tests and Modeling on a Combined Heat and Power Biomass Plant. Energies (2019), 12, 2615; doi:10.3390/en12132615

7. E. Provata, D. Kolokotsa, S. Papantoniou, M. Pietrini, A. Giovannelli, G. Romiti, Development of optimization algorithms for the Leaf Community microgrid. Renew. Energy (2015), 74, 782-795.

8. E. Stamponi, F. Giorgini, N. Lattanzi, N. Di Lisa, E. Moretti, Analisi preliminare del funzionamento di una microgrid termica alimentata da un cogeneratore a biomassa: il caso di studio Loccioni. In 20th CIRIAF National Congress, 1617 April 2020, Perugia, Italy (2020).

9. Burkhardt. Planning Documentation - Wood Gasifier V4.50 Smartblock 50T CHP (2018).

10. Burkhardt. Data Sheet - Wood Gasifier Burkhardt V4.50 with Cogeneration Unit smartblock 50T (2017).

11. MyLeaf Platform - Loccioni Group. Available online: https://myleaf2.loccioni.com

12. F. Patuzzi, et al., Small-scale biomass gasification CHP systems: Comparative performance assessment and monitoring experiences in South Tyrol (Italy), Energy, n. 112, (2016), 285 - 293

13. F. Cotana, et al., Pollutant emissions of a biomass gasifier inside a multifuel energy plant, Atmospheric Pollution Research (2019), doi.org/10.1016/j.apr.2019.09.007.

\section{List of acronyms}

$\begin{array}{ll}\text { EU } & \text { European Union } \\ \text { RES } & \text { Renewable Energy Sources } \\ \text { CHP } & \text { Combined Heat and Power } \\ \text { nZEB } & \text { Nearly-Zero Energy Building } \\ \text { HVAC } & \text { Heating Ventilation And Air Conditioning } \\ \text { HP } & \text { Heat Pumps } \\ \text { PV } & \text { Photovoltaics } \\ \text { BES } & \text { Battery Energy Storage } \\ \text { POD } & \text { Point Of Delivery }\end{array}$

